\title{
FAMÍLIA \\ E MOVIMENTO OPERÁRIO: \\ A anarquia dentro de casa'
}

Isabel Aparecida Bilhão²

A partir do período que poderíamos denominar tempos modernos - principalmente após a Revolução Industrial - há uma grande revolução na forma de distribuição da afetividade, e o sentimento que antes estava difuso entre vários sujeitos, naturais e sobrenaturais, passa a concentrar-se então no interior da família, correspondendo a uma supervalorização da família nuclear burguesa predominante na nova sociedade, em detrimento a outras formas de convivência. Doravante, a vida de cada trabalhador será partilhada, preferencialmente, entre dois pólos, o de seu trabalho e o de sua família, inclusive como uma forma disciplinadora de sua conduta, sendo que este trabalhador apenas eventualmente poderá escapar à regra, buscando, entre o espaço da família e o do trabalho, um lugar de encontro e animação, os bares, os cafés, a cidade. A implacável regra de conduta para aqueles que não trabalham, ou não trabalham mais (mulher, criança velho), é a

Este artigo só se tornou possível graças a uma entrevista que me foi concedida pelo Sr. Marat Martins Budaszewski, filho de Zenon de Almeida (Budaszewski) e Eulina Martins Budaszewski. A ele, fonte viva e lúcida de nossa memória operária, gostaria de dedicar esse trabalho.

2 Mestranda em História do Brasil do Curso de Pós-Graduação em HistóriaPUCRS. 
de que suas vidas devam ser inteiramente absorvidas pela relação familiar ${ }^{3}$.

O âmbito familiar é o mundo da casa, da relação pais e filhos, do espaço da organização do tempo e da vida fora do trabalho. É, por excelência, segundo as normas da nova coexistência social, o local ideal para utilizar o tempo livre, que deve ser gasto com as individualidades familiares, o lazer familiar, o cuidado do jardim ou da horta, a ida à missa dominical. Âmbito que exclui, portanto, as vivências coletivas, a participação política, ou qualquer forma de sublevação à ordem estabelecida pelo mundo do trabalho ${ }^{4}$.

É essa, portanto, a regra que passa a predominar - juntamente com o desenvolvimento industrial, o avanço tecnológico e a urbanização das cidades - como característica civilizadora do mundo Ocidental moderno, a partir do século XIX. Nesse contexto, como ressalta Michel Mafessoli, "o burguesismo triunfante tinha como vetor essencial o individualismo, [e $\mathrm{e}$ ] modelo comunitário foi progressivamente reprimido"5.

Entretanto, este artigo propõe-se a não falar da regra, mas da exceção. A intenção aqui é contar, ainda que resumidamente, a história de uma família que, embora não sendo a única, torna-se singular por fugir às determinações de seu tempo, abrindo-se a uma convivência exterior ao núcleo familiar que acabará por mesclar os afetos e as solidariedades familiares com a militância operária.

A família em questão chama-se Martins-Budaszewski ${ }^{6}$ - uma das mais importantes famílias de líderes operários das décadas de 10 e 20, que muito influiu, não só na organização operária em Porto Alegre, mas também dela participou no centro do país. Essa família torna-se exceção à regra, justamente porque seus membros compartilhavam de

3 ARIÉS, Philipe. "A família e a cidade". In: VELHO, Gilberto \& FIGUEIRA, Sérvulo (org.). Família, Psicologia e Sociedade. Rio de Janeiro: Ed. Campus, 1981 , p.16 e 17.

4 Uma discussão interessante acerca da questão familiar e o mundo do trabalho é realizada por RAGO, Margareth. Do Cabaré ao Lar: a utopia da cidade disciplinar: Brasil: 1890-1930. Rio de Janeiro: Paz e Terra, 1985, p.163-204.

5 MAFESSOLI, Michel. O Tempo das Tribos, o declínio do individualismo nas sociedades de massa. Rio de Janeiro: Forense-Universitária, 1987. p. 105.

6 A maioria das informações sobre os componentes dessa família me foi confiada pelo Sr. Marat em entrevista realizada no dia 21 de junho de 1996. As demais informaçōes, retiradas de outras fontes, apareceram com nota explicativa própria. 
uma ideologia - o anarquismo - que está além do mundo familiar, e que pretende contrapor-se ao espírito de seu tempo, isto é, à moderna sociedade capitalista.

Se, por um lado, a ideologia e a militância estão acima da convivência familiar, por outro lado, é indispensável à manutenção da militância essa interação de afetos e solidariedades. A solidariedade com os membros do grupo - aqueles que compartilham as mesmas utopias sociais, a mesma revolta contra o sistema - pode servir, arrisco-me a pensar, como o cimento que os mantêm unidos na falta de uma instituição mais permanente como, por exemplo, o partido político.

O enfoque que pretendo dar a esse trabalho parte do princípio de que, em muitos casos, a interação de solidariedades e afetos entre família e a militância é tão intenso que se torna impossível separar aquilo que seria a conduta familiar da organização operária. Dessa forma o movimento passa, literalmente, a ocorrer dentro de casa, da mesma forma que os membros da família passam a integrar as ações e agitações do movimento.

Essa interação, ou melhor dizendo, essa mistura de signos poderia, em meu entendimento, ser denominada de hibridização de códi$\operatorname{gos}^{7}$, termo que tomo emprestado de Gilberto Freyre e que, neste contexto, é utilizado para expressar a influência recíproca entre a vida familiar, individualista, e a vida na militância operária, que se apóia na coletividade.

A idéia síntese desse artigo aparece de maneira contundente em uma frase dita por Marat Martins Budaszewski em nossa entrevista: $A$ propósito das panelas da Eulina, ... aquele material da bomba de $1917^{8}$ que foi feita pelo Zenon, porque ele entendia do assunto, foi

7 Essa expressão é usada por Gilberto Freyre, em Casa Grande \& Senzala, para definir aquilo que ele chama de "bambo equilíbrio de antagonismos" em tudo que permeia a vida dos brasileiros. Este é, segundo o autor um signo da civilização brasileira, essa capacidade de assimilação e ao mesmo tempo de transformação de tudo que nos chega do exterior. FREYRE, Gilberto. Casa Grande \& Senzala. Formaçāo da Família Brasileira sob o regime da economia patriarcal. Rio de Janeiro: Record, (29. ed.) 1992 (capítulo I).

8 Quanto à greve de 1917 um importante estudo sobre o assunto foi realizado por SILVA Jr. Adhemar Lourenço. "Povo! Trabalhadores!": Tumultos e movimento operário (estudo centrado em Porto Alegre, 1917). Porto Alegre: IFCH-UFRGS, 1994 (dissertação de mestrado), p. 216-343. 
misturado com as colheres, que ela utilizava na cozinha e com as quais eu inclusive, mais tarde, comi a comida feita com elas.

Quanto à história da família propriamente dita, prefiro ausentarme por ora da narrativa e reservar alguns comentários para o final, deixando que o próprio Marat fale sobre ela.

Segundo suas palavras: vovô Ingnaci Budaszewski também era um homem socialista, eu o conheci no fim da vida e ele me admirava muito, evidentemente porque eu era filho do Zenon... isso deve ter influenciado também o jovem, o moço, o menino Zenon. Vovô era um oficial sapateiro formado em Varsóvia e que se especializou em Porto Alegre em sapatos femininos. Casou-se em Varsóvia e veio com a esposa, o Zenon nasceu aqui, nasceu nos Navegantes, no ano de 1892. Vovô tinha um português perfeito, não tinha um mínimo resquício de sotaque polonês...

Se meu avô não conseguiu, pelo menos pretendeu que os seus filhos tivessem uma educação muito boa. E o Zenon aprendeu, de berço, o ídiche e o polonês, mas como não havia aqui outras escolas, ele foi matriculado numa escola alemã, então ele dominou também o alemão, eu o ouvi muitas vezes falar alemão... E aprendeu também, entre outras coisas, música, canto, violão. Adquiriu uma base cultural muito firme. Era um homem que tinha cultura matemática, ele tinha uma tábua de logaritmos, tábua astronômica... Acredito que na escola alemã ele deve ter cursado até o fim do primário...

E nas viagens pela Europa ele acrescentou muito mais... Zenon era um homem alto, magro ... aos quatorze anos, o vovô Ignaci perdeu a primeira esposa e casou-se novamente, e aquela questão de madrasta... Ele divergiu com ela e saiu de casa, já era um tipo espadaúdo, ele já era profissional, porque o pai lhe ensinou. Foi cortador, foi modelista de calçados, certa vez o vovô revelou a mim que tinha muita vaidade do filho, porque ele tinha extrema habilidade...

Depois que saiu de casa ficou trabalhando em Porto Alegre ainda alguns anos, naquela época os navios veleiros vinham a Porto Alegre e - isso eu soube dele mesmo - ele se engajou num veleiro holandês como moço de bordo. Quando voltou, era marinheiro... ele deve ter embarcado com 18 ou 19 anos e esteve cinco anos fora, fazendo navegação de cabotagem.... 
Essa vinda do veleiro a Porto Alegre era um fato excepcional, porque aquele era um quatro mastros, um veleiro grande... ele deve ter recebido uma carga muito grande para cá e trouxe. Mas lá na Europa ele fazia o trabalho de cabotagem e então visitava todos os portos do Mediterrâneo, todos os portos do Báltico e todos os portos do Atlântico e com isso inclusive Zenon aumentou seu cabedal de idiomas, se tornou um poliglota, eu o ouvi, muitas vezes, falando com italianos, espanhóis, alemães, judeus, eu aprendi francês com ele; seu último esforço ainda foi o de melhorar o seu conhecimento de turco.

Acredito que Zenon deva ter ingressado nos grupos anarquistas espanhóis, mas isso ele nunca chegou a me confirmar. Lá na Europa ele conseguiu uma boa biblioteca, e acredito que também lá ele conseguiu os livros de Química Industrial. Essa base cultural que ele adquiriu aqui, numa escola alemã, creio que foi essencial...

Já minha mãe, Eulina Martins Budaszewski, é filha de Teófilo Augusto Martins e de Laura Azambuja von Reichenbach Martins. Laura, mãe de Eulina, é filha de um ex-oficial do exército prussiano, Henrique Felipe von Reichenbach, que vem para o Brasil ainda no $I^{g}$ Império e recebe do Imperador a tarefa de demarcador de terras no interior do Estado, na região do Jacuí, seu sobrenome demonstra ligação com a nobreza prussiana...

Minha mãe estudou em São Gabriel da Estrela ${ }^{9}$ com a professora Malvina, que também era uma pessoa ideologicamente engajada. E não era só a professora Malvina, eles, os irmão Martins, foram para a professora Malvina, porque havia alguém que os levou a estudar com ela; este alguém foi o Teófilo Augusto Martins, meu avô materno. Este homem foi analfabeto até os 25 anos, quando aprendeu a ler e a escrever, ele passou a adquirir livros, os quais lia para os filhos. Provavelmente mantinha intercâmbio com a professora Malvina. Teófilo era um grande crítico da Igreja, lia os livros maçons e, apesar de não ser um maçom, ele criticava a Igreja. E aqueles meninos e aquelas meninas, todos ficaram ideologicamente armados contra a Igreja, e quem se arma contra a Igreja, ou contra qualquer religião, tem uma ideologia diferente. E eles até certo ponto eram intolerantes... Todos estudaram com a professora Malvina e os meninos aprenderam tipografia...

9. Naquela época São Gabriel da Estrela era distrito de Lajeado, atualmente é o município de Cruzeiro do Sul. 
Eulina era uma mulher fisicamente forte, trabalhou na lavoura, no cabo do arado, como seus irmãos. Mas há uma coisa interessante, porque sendo da lavoura, eram intelectuais. Havia uma espécie de veneração pela professora Malvina, e eu digo isso com certeza absoluta. Porque ideologicamente essas pessoas estavam no mesmo grupo... A professora Malvina, por leituras, por pesquisas chegou a essas idéias libertárias; pode ter avançado muito mais que meu avô Teófilo, porque tinha um estudo mais sistemático.

Minhas tias e minha mãe eram mulheres normais, mulheres bonitas, mas que tinham um algo mais... que os homens adoram muito, eram mulheres intelectuais, então seus casamentos também foram motivados ideologicamente, nos grupos que freqüentavam, na escola Eliseu Réclus, na Escola Moderna, conheceram seus companheiros... ai surge o amor... surge o namoro e se casam...

O mais interessante é que eles defendiam o amor livre, mas na concepção do amor livre estava o respeito total e irrestrito enquanto companheiros, da mesma forma que, se o casal se separava, a responsabilidade do pai pelo filho era automática, e isso exige muito das pessoas...

A ida de Zenon e Eulina para o Rio de Janeiro ocorre da seguinte maneira: saíram de Porto Alegre, depois das greves daqui (1917/18). A comissão organizada aqui, na greve de 1917 - que se constituía de Polydoro dos Santos ${ }^{10}$, Henrique Martins ${ }^{11}$ e Zenon de

10 Polydoro Santos era gráfico e jornalista, chegou a ser dirigente da FORGS, foi um dos fundadores da escola Eliseu Réclus, importante líder sindicalistaanarquista, escreveu no jornal A Luta, amigo pessoal de Zenon de Almeida e de Henrique Martins. Para maiores informações procurar em: MARÇAL, João Batista. Os anarquistas no Rio Grande do Sul. Porto Alegre: UE/Porto Alegre, 1995, p.157-162. e GERTZ, René (ed.). Memórias de um imigrante anarquista (Friedrich Kniestedt). Porto Alegre: EST, 1989, p.124-146.

11 Henrique Martins, importante liderança sindicalista, também postulante de idéias anarquistas, é o irmäo mais velho de Eulina, tio de Marat, foi o primeiro irmão a vir para Porto Alegre, aqui chegou em 1906, tipógrafo de profissão, participou, com Polydoro Santos da fundaçāo de Escola Eliseu Réclus, da redação do jornal A Luta. Em 1911, quando do acirramento da disputa pela direção da FORGS entre os socialistas, liderados por Xavier da Costa, e os sindicalistas. Respondeu a um processo crime por calúnia e difamação movido contra ele por Xavier da Costa, que lhe custaria, além de $450 \$ 000$, quatro meses de prisão, caso não tivesse fugido para o Rio de Janeiro e adotado o pseudônimo de Cecílio Vilar. Processo crime: $\mathrm{n}^{2} 298$, maço 15, estante 29. Arquivo Público, réu Henrique Martins, 1911. 
Almeida - não negociava com a Prefeitura; a greve foi um movimento local, negociado com o Governo do Estado, e terminou com um acordo. Algumas categorias não se submeteram, que eram exatamente as do grupo dos anarquistas; continuaram se reunindo na sede da União Operária, e a União Operária acabou sendo invadida pela polícia, mas de qualquer forma nada pesava contra eles. Mas, segundo suponho, Polydoro fazia parte daquele grupo que continuou na agitação e na greve, e ele teve que sair daqui fugido, o Polydoro...

Aquela greve de 1917 foi violenta... pelo seguinte: os padeiros eram atacados, os animais eram desatrelados, ele enxotavam os animais, distribuíam o pão para a população, viravam e até dinamitavam as carroças, e isto é uma violência, mas tem mais uma violência que quase ninguém sabe. Por que o comércio todo fechou? Fechou pelo seguinte, e isso eu soube pela Eulina e pelo Platão Martins: de noite, as casas comerciais tinham as portas de madeira perfuradas com arco de pua, e esguichavam petróleo ou piche para dentro dos estabelecimentos, foi só uma noite e os resultados apareceram, todo mundo fechou. Outra coisa - como faziam a distribuição dos jornais, ou dos volantes chamando para a greve? Armando Martins ${ }^{12}$ tinha uma tipografia, então os cinemas naquela época distribuíam volantes à população, dizendo como seriam os filmes... isso era feito geralmente de noite, colocando os volantes por baixo das portas. Os agitadores imprimiam um manifesto do mesmo tamanho, inclusive escrito pelo Henrique, e colocavam em baixo dos volantes dos cinemas. Platão Martins fez isso muitas vezes, e outros filhos de anarquistas também, durante a greve. Como se estivessem distribuindo volantes dos cinemas, colocavam o manifesto nas casas. E tinha "o rato branco" (policial do quarteirão), que pedia para ver o que eles estavam distribuindo. Eles imediatamente entregavam um volante do cinema e continuavam sua distribuição. Como a cidade era pequena isto fez com que a greve fosse alimentada ideologicamente de forma constante. E jamais essa tática foi descoberta...

12 Armando Martins também é tio de Marat, tipógrafo, veio para Porto Alegre por volta de 1906, foi um dos fundadores da Uniāo dos Tipógrafos. MARÇAL, Os anarquistas..., p. 111-112. 
Em 1917 participaram diretamente Zenon e Reinaldo Geyer ${ }^{13}$ na fabricação da bomba, Eulina que ajudou, Espertirina ${ }^{14}$ (com 14 ou 15 anos), que levou a bomba escondida e entregou ao Djalma $\mathrm{Fe}$ ttermann ${ }^{15} \ldots$

Oito horas de trabalho... as reivindicações deles eram reivindicações econômicas, condução mais barata para os trabalhadores, feiras livres, barateamento dos gêneros de primeira necessidade a partir do pão, porque com a guerra houve uma especulação tremenda....

Depois disso Zenon foi com Eulina para Rio Grande; lá ele logo arrumou trabalho, ele tinha conhecimento de química industrial e, dominando bem o inglês, ele foi trabalhar na Swift. Nessa empresa eles perceberam que tinham um homem que falava inglês e que podia transmitir as ordens do engenheiro muito melhor do que qualquer outro. Mesmo assim em Rio Grande ocorreram encontros violentos com a Brigada, porque também havia um forte movimento operário. Depois passou a Pelotas, onde eu nasci, em 1918, na sede da União Operária de Pelotas, onde minha família estava abrigada por ainda näo ter encontrado casa. Isso faz parte dessa solidariedade... em Pelotas onde trabalhava na Arno, Zenon foi localizado pela polícia, $e$ os camaradas anarquistas perceberam isto, e aconselharam que ele saísse, e de lá ele foi para Santa Maria, onde nasceu minha irmã Laura...

O motivo das perseguições é que ele chegava nesses lugares e o prelo começava a funcionar, e isso agitava muito o lugar; e foram lugares já tradicionalmente agitados, que já tinham um movimento

13 Reinaldo Geyer, médico de profissão, militante anarquista, foi um dos principais professores da Escola Eliseu Réclus, também foi redator do jornal A Luta. MARÇAL, ibid., p. 79-82.

14 Espertirina é a irmã mais nova da família Martins, participou das agitações operárias do período, foi aluna da Escola Moderna, onde conheceu seu futuro marido Arthur Fabião Carneiro. Morou muitos anos em companhia da irmã Eulina e do cunhado Zenon em São Paulo. MARÇAL, ibid., p.107-110.

15 Djalma Fettermann casou-se com Dulcina Martins, portanto é cunhado de Eulina e Zenon. Importante líder anarquista, em Porto Alegre trabalhou como metalúrgico, ourives e gráfico, participou da fundação da Escola Eliseu Réclus, da redação do jornal A Luta. Extremamente culto, falava fluentemente o francês, em 1919 fez concurso para os correios; passando em um dos primeiros lugares, optou por trabalhar no Rio de Janeiro (informaçôes retiradas da entrevista com Marat Martins Budaszewski). Ver também: MARÇAL, ibid., p. 75-78. 
operário em curso; o prelo do Zenon era um meio de expressão e agitação, esse prelo foi até Santa Maria. Me lembro do prelo do Zenon trabalhando e da Eulina ajudando. Em Santa Maria Zenon passou a trabalhar na Viação Férrea, que ainda não era do governo. Ele não tinha crime, o crime era a própria agitação. Lá em Santa Maria o prelo foi apreendido. Em 24 horas a família foi colocada com todos os seus trastes num vagão especial da Viação Férrea, vigiado, e deixado na cidade de São Paulo. Não sei se por consenso de todos, resolveram ir para o Rio de Janeiro. O contato com Edgar Leuenroth ${ }^{16}$ já ocorre na chegada, nesse sentido os anarquistas eram muito solidários...

Então foram para Rio de Janeiro, mas na viagem eu fiquei com paralisia infantil, fui tratado no Rio de Janeiro. Essa viagem de Santa Maria ao Rio de Janeiro levou aproximadamente uma semana... Fomos metidos dentro do vagão à força, na verdade fomos expulsos na maior arbitrariedade....

Também por causa dos contatos com camaradas anarquistas, fomos morar na Ilha do Governador, na Praia da Engenhoca, na casa de outra família de anarquistas que estava morando lá.

E Zenon conseguiu emprego de soldador na Anglo Mexican Co. Ltd. (atualmente Shell). Mas falava inglês e seus chefes, que eram ingleses, perceberam a facilidade de comunicação e ele logo em seguida passou a apontador. Na qualidade de apontador ele esteve poucos meses, e foi designado para chefiar o depósito dessa empresa em Campos, que ficava muito próximo da cabeceira da ponte velha do lado de Guarulhos, era um dos depósitos de gasolina e querosene. Ele, como soldador, fazia o trabalho de consertar as latas onde eram embalados os produtos....

Zenon não voltou mais a Porto Alegre, faleceu em 1939, relativamente com pouca idade; morreu repentinamente, de uma parada cardíaca, ao lavar-se de manhã. Nesse período ele era tradutor da Embaixada Polonesa, isso eu fiquei sabendo por intermédio dos anarquistas do Rio de Janeiro quando, em 1950, estive lá trabalhando no O jornal, e eles me falaram sobre o Zenon, sobre as coisas do Zenon, ele então terminou como tradutor dos materiais poloneses para o português e vice-versa.

16 Edgar Leuenroth é tipógrafo, anarquista, importante líder operário paulista. Redigiu, entre outros, o jornal Terra Livre, 1905. RAGO, op. cit., p. 15. 
O típico desses anarquistas que eu conheci, muitos deles meus tios e tias, é que eles não eram membros da classe dominante que desciam à classe operária, eles eram operários que subiam à classe média, e que eventualmente passavam até a ser indivíduos ricos, por serem detentores de um saber, de uma especialização profissional pouco difundida...

Mas, Zenon não enriqueceu. Porque ele era um homem que estava totalmente dedicado à causa, ele não via outro motivo na vida, ele e Eulina eram totalmente despojados, até mesmo por uma questão de coerência pessoal com a causa.

Tínhamos em casa um pequeno laboratório, onde papai fabricava éter. Toda a aparelhagem de fabricação de éter e também de perfumaria, por exemplo, era feita por ele... Tinha um auxiliar, Platão Martins... Chegou a fabricar também um espécie de brilhantina, que servia para alisar o cabelo que era muito procurado pelas moças $e$ rapazes negros da região. Com isso havia uma fonte extra de dinheiro, também fabricou colorau - eu mesmo entreguei colorau nas casa dos arredores...

Em 1926 ou 1927 ele esteve no Rio de Janeiro e adquiriu uma galena, já com válvulas e dai ele se interessou pelo problema do rádio, e em 1934 com o engenheiro alemão Frank Rohl, que não falava português, montaram a primeira emissora da cidade, mas não conseguiram registro, porque meu pai foi oposição à Revolução de 30; chegou inclusive a estar no ar em regime experimental, mas tiveram de cessar as atividades... Zenon ia regularmente a Niterói prestar os exames do preparatório e em 1928 ele conseguiu o diploma de químico industrial; tinha até muita vaidade por isso...

No entanto, Zenon era um homem que se vestia simplesmente, não usava nada fora do comum, ele era calvo, tinha uma calva muito grande, mesmo botando o boné aparecia a calva, mas não tinha nada fora do comum, era muito requisitado no interior dos cafés por outros homens que queriam saber sua posição. E ele estava sempre na oposição, por exemplo, na Revolução de 30; inicialmente ele apoiou a Revolução, mas em seguida ele percebeu a que os seus líderes tinham vindo...

Da mesma maneira, Zenon apoiou a Revolução de 1924, distribuiu inclusive a carta de Prestes, mas ele nunca foi prestista, ou seja, essa idolatria pelo indivíduo não faz parte do ideário anarquista. 
Também na revolução de 1924 o Nino (Antônio Martins) ${ }^{17}$ foi partícipe em São Paulo, assinou o manifesto dos gráficos, pedindo armas para defender a Revolução... O Nino foi para a nossa casa, $e$ aí eu ouvia suas conversas com Eulina, Zenon e os outros. Ele usava uma barba que parecia de um profeta; tanto o Djalma Fettermann quanto o Zenon e a Eulina recomendaram: "tira essa barba porque essa barba te identifica"... Tipógrafo barbudo, só ele. E ele estava na mira da polícia. O que aconteceu - foi para o Rio de Janeiro, foi trabalhar numa tipografia, prenderam... Primeiro esteve no navio-prisão e depois foi mandado para a Clevelândia... Ele era relativamente jovem, era dos irmão mais jovens... Ele era extremamente radical, até mesmo temido... não pelos camaradas, temido pelos elementos da burguesia... O Nino foi para Campos auxiliado pelos anarquistas, ficou hospedado em nossa casa e tinham longas conversas; eu guardei por muito tempo uma lata de fumo vazia que pertenceu a ele e depois dei para minha mäe usar nas costuras. Como também tinha anarquistas no correio, onde o Djalma trabalhava, ao sair de Campos, ele foi para o Rio de Janeiro "fora de mala" (era o funcionário do correio que ia até um determinado lugar, completava o seu trabalho e depois voltava, sem trabalhar). Ele voltou para o Rio de Janeiro como se fosse um "fora de mala", deram um uniforme para ele, eu vi inclusive a despedida, ele vestido como carteiro, mas com aquela barba...

17 Nino, Antônio Martins, era dos irmãos mais novos da família Martins, tipógrafo como os irmãos, e também anarquista, procurava organizar greves nos grandes jornais onde se empregava como $O$ Diário e a Última Hora. Utilizando, como forma de protesto, a sabotagem, empastelando páginas desse jornais. Devido à sua tática de militância também foi processado, e teve de sair de Porto Alegre, indo viver em São Paulo e no Rio de Janeiro, entretanto, envolveu-se novamente em agitações operárias sendo preso pelo governo Arthur Bernardes e depois deportado para a Clevelândia, espécie de prisão/campo de concentração para presos políticos no Oiapoque, onde veio a falecer um ano depois, em 1926. Processocrime n² 949. Arquivo Público, réu: Nino Martins. Maço 59, Estante 29, 1918. Apud. SILVA Jr. Povo! Trabalhadores!..., p. 254. Ver também PETERSEN, Silvia Regina Ferraz. "Cruzando Fronteiras: As pesquisas regionais e a história operária brasileira. Anos 90. Porto Alegre: UFRGS, n. 3, jun. de 1995, p. 138140. 
O Henrique faleceu em 1918, em Passo Fundo, onde adquiriu a gripe espanhola; ele era um grande orador, escrevia muito bem, era bilingüe, falava o castelhano perfeitamente, trabalhou inclusive na Argentina, em Buenos Aires, depois que voltou do Rio de Janeiro... Era uma figura reverenciada por todos, morava numa casa que ficava ali na Oswaldo Aranha, próximo de onde fica hoje a escola de arquitetura.

O Polydoro era mais velho, já era um dirigente... O Zenon nunca foi um dirigente sindical, ele era o organizador, um agitador, mas nunca participou da direção de sindicato ou da FORGS; ele falava na frente das fábricas fazia, como fazem hoje, os piquetes. Agora, o Polydoro é que era considerado incontestavelmente líder, todos o consideravam, suponho inclusive que ideologicamente ele teria um domínio muito maior de conhecimento, sendo um homem mais velho... nunca formaram partido, e tiveram muita autonomia... Os anarquistas eram partidários de escolas para os trabalhadores, de universidades para os trabalhadores... Eram partidários da ação concreta...

A respeito da autonomia do operariado eu ouvi muitas vezes conversas entre Djalma e Zenon, que diziam o seguinte: que este fato dos indivíduos poderem optar por uma posição especial enfraquecia o movimento, isso era unânime, porque Djalma era representante de uma entidade internacional anarquista... e foi um homem engajado até o fim da vida. Por ser muito radical nunca quis nem mesmo participar, mais tarde, do Partido Comunista. Mesmo quando sua esposa e filho passaram a militar no Partido Comunista..

Quanto à ideologia, Zenon e Djalma citavam muito Proudhon, esse nome eu ouvi desde muito cedo, Bakunin, nunca ouvi, nem Marx... nas conversas que eles tinham ao redor da mesa e que eu ficava ali ouvindo.

Já quanto a Eulina, minha mãe, ela era, em primeiro lugar uma mulher muito simples, muito despojada, com uma característica interessante: nem Eulina nem Espertirina nem Dulcina... nunca usaram jóias... Eulina era até radical: "não uso essas porcarias". Ouvi essa expressão dela muitas vezes, era uma mulher de relativa beleza, vestia-se normalmente, era muito admirada pelos homens, porque era uma mulher que discutia problemas políticos. Ela, mais tarde, foi militante do Partido Comunista e morreu como membro do partido, e tinha com ela uma parte dos arquivos do P.C. Era uma mulher simples, fazia nossa comida, ao mesmo tempo em que era militante ativa 
do movimento anarquista e mais tarde do Partido Comunista... Tinha sobre mim, as irmãs e as netas uma influência muito grande, sem nunca precisar se impor, ou nos bater...

Os anarquistas educavam os membros de sua família, os filhos, nos conceitos anarquistas, pelos quais as pessoas não abandonam a causa... Fui ensinado em casa, porque tinha problemas de saúde para ir à escola, a ler e a escrever com meus pais, numa espécie de livro, que não era uma cartilha, feito pelo Zenon. Eu aprendi muito, porque o papai tinha uma capacidade didática natural. $O$ conhecimento anarquista era passado em nossas conversas diárias... Espertirina, quando saía comigo, me levava pela mão, aplicando a ideologia. Esse triângulo, Djalma Fettermann, Espertirina Martins, Zenon de Almeida só se dissolveu em 1935, quando ela veio para Porto Alegre casada com Arthur Fabião Carneiro, que ela conheceu na Escola Moderna, onde os dois foram alunos....

Dulcina Martins e Djalma Fettermann casaram-se em Campos na casa de Zenon e Eulina, Espertirina e Arthur casaram-se na casa de Djalma e Dulcina no Rio de Janeiro...

O grupo de anarquistas em Campos era grande, muitos eram do Rio Grande do Sul, de Porto Alegre, que iam para Campos e procuravam o Zenon....

A Escola Parobé em Porto Alegre foi um reduto de anarquistas, muitos professores daqui pediam transferência para outras escolas de aprendizes e artífices de São Paulo, e a casa de Zenon era um ponto de referência e até de abrigo. Nesta época estávamos morando em uma casa muito grande... e ali inclusive ocorriam muitas reuniões, e pelas conversas que se travavam eu percebia que se tratava de um grupo de anarquistas

Zenon chegou a militar no Partido Comunista, porque este era o partido que naquele momento estava mais próximo de suas idéias, mas não repudiou, de forma alguma, às idéias anarquistas... Essas pessoas - Zenon, Eulina, Espertirina, Djalma, Nino - não eram simples militantes anarquistas eles tinham uma vivência completa do anarquismo... 
São muitas as possibilidades interpretativas que se apresentam após esse relato de história familiar, e acredito que os demais pesquisadores do tema também em muito poderão servir-se dele. Entretanto, o objetivo desse artigo é o de ressaltar a importância da afetividade e da solidariedade como componentes relevantes da história dos trabalhadores.

Podemos ver que a história de uma família, como a desse caso, pode conter a própria história do movimento operário de uma época, e, arrisco a supor, que muitas vezes o que garante a continuidade e motivação ao movimento são justamente essas ações concretas de solidariedade.

Ou seja, é na vida cotidiana que se forma a coexistência social onde ocorre permanentemente a relação entre o indivíduo e o grupo, onde o indivíduo não está isolado mas, ao contrário, liga-se a uma comunidade por uma série de laços de afeto, de costumes cotidianos, de ações. Acredito que são exatamente essas ligações afetivas e essas ações solidárias, por muito tempo esquecidas pela lógica da modernidade - que privilegia uma abordagem econômica, um projeto político e a atomização individual ${ }^{18}$ - que impulsionam as utopias presentes no movimento operário.

Contando com essa solidariedade, é que militantes como os irmãos Henrique e Armando Martins vêm para Porto Alegre, sendo do interior, não conhecendo a cidade, dependerão da ajuda daqueles que já estão estabelecidos para conseguir morar de pensão ${ }^{19}$ arranjar emprego, participar da militância. Da mesma forma que, tão logo estabelecidos, irão participar desses laços recíprocos de solidariedade.

É, evidentemente, em nome da causa operária que se fundam as escolas e os jornais anarquistas, que ocorrem as greves e agitações. Mas, ligando essas pessoas estará uma forte afetividade, que gera um sentimento de confiança. Essa afetividade não procede somente dos laços familiares que os unem, procederá também da solidariedade e da amizade que se geram no interior do movimento, abarcando outras pessoas, dessa forma, ocorrem o amor, o namoro e os casamentos, gerando novos laços de parentesco no interior da militância.

18 MAFESSOLI, op. cit., p. 115-117.

19 Fica claro nos depoimentos das testemunhas de defesa de Henrique Martins que todos eram seus companheiros de pensão. Processo-Crime 298, cit. 
Nesse contexto, torna-se muito difícil separar o que em um determinado momento é relação afetiva, amizade, solidariedade familiar, da organização operária.

Para exemplificar essa questão, gostaria de lembrar um episódio, já mencionado anteriormente, em que Henrique Martins se vê envolvido em uma situação bastante delicada, ao ser processado por Xavier da Costa (figura com a qual rivalizava política e ideologicamente dentro do movimento operário). É condenado a pagar, como multa, a quantia de $450 \$ 000$, mais as custas de seu advogado, Dr. Raymundo Alexandre Pereira, além de ser condenado a quatro meses de prisão. Naquele momento, alguns de seus amigos, tipógrafos como ele, companheiros de pensão e militância, não vislumbram outra saída senão sair a público pedindo ajuda para saldar as dívidas advindas do processo. A ação de solidariedade torna-se pública em Porto Alegre e esses amigos servem inclusive de piada nas páginas do jornal onde escreve Xavier da Costa $^{20}$.

De qualquer forma, a sentença de prisão é mantida. Henrique Martins escapa então para São Paulo, onde passa a usar o pseudônimo de Cecílio Vilar. Como essa rede de solidariedades não tem limitações geográficas, Henrique Martins irá contar no centro do país com a mesma ajuda que, mais tarde, sua irmã Eulina e seu cunhado Zenon receberão.

É difícil mesmo imaginar o futuro da militância sem esse sentimento de solidariedade, é na casa de companheiros, nas sedes das associações que muitas vezes os militantes em fuga irão se abrigar ali, eventualmente, ocorrerá um casamento, o nascimento de um filho.

Igualmente interessante é perceber que essa mistura, essa hibridização entre os códigos familiares e de afetividade irá transpor, como já referi anteriormente, as barreiras geográficas, não se restringindo a uma ou outra cidade, a um ou outro estado, espalhando-se por onde estão as pessoas e o envolvimento afetivo ajudando a inaugurar novos núcleos de militância, a garantir a fuga e a sobrevivência.

Resumindo e concluindo, a transmissão da ideologia não ocorre apenas de maneira formal, durante greves e agitações, tampouco ocorre apenas nos espaços sindicais ou nas federações. A organização operária encontra espaço fértil também em volta das mesas dos bares, dos cafés, no interior das casas e das pensões, da mesma maneira que 
a educação dos filhos, o convencimento dos novos participantes, transborda de afetividade, como no caso de Espertirina que aplica a ideologia levando seu sobrinho, Marat, pela mão.

A organização de estratégias e de agitações, e mesmo dos textos que serão publicados nos jornais anarquistas, muitas vezes ocorrem em conversas informais, entre familiares e amigos. O movimento operário convive, portanto, com a solidariedade e o afeto. E esses são componentes importantes, que merecem ser incorporados em nossos estudos sobre a memória operária brasileira. 